\title{
Digitisation of Healthcare Products and the Democratization Continuum of the Healthcare System in China : A Systematic Review
}

Henry Asante Antwi ${ }^{*}$, Tamires Lizandra Andrade Paixao ${ }^{2}$, Maxwell Opuni Antwi ${ }^{1}$

${ }^{1}$ School of Management, Jiangsu University, 301 Xuefu Road, Zhenjiang, P.R. China

${ }^{2}$ Future Academy of Science and Technology, 3768 Hunan Highway, Shanghai, P.R China

\begin{abstract}
Article Info

Volume 8, Issue 4

Page Number: 266-283

Publication Issue :

July-August-2021

\section{Article History}

Accepted : 20 July 2021

Published: 30 July2021

Typical of most industries, digitisation of healthcare products, services and models of E-Commerce is democratizing the current healthcare system in China while unlocking new previously inaccessible healthcare segments. This monumental convergence of healthcare industry with IT is part of a larger evolution and growth of E-Commerce from simple search portals for purchasing goods and services to more integrated digital marketplace that incorporates personalized experience and informed purchase decision making into online behaviours. The result is the manifestation of a new era of healthcare consumerism, as healthcare customers demand retail-like buying experience. We performed a comprehensive systematic scoping review of published data to identify how E-Commerce is complementing the traditional healthcare delivery system in China. We note that healthcare E-Commerce is facilitating the reconstruction of the healthcare value chain in China and at the same time is helping health facilities to reengineer operations and service processes. Our study highlights the important role E-commerce is playing in the healthcare industry in China.
\end{abstract}

Keywords : E-Commerce, digital marketplace, Systematic Reviews and MetaAnalyses, Quality of Reporting of Meta-Analyses, PRISMA Model

\section{INTRODUCTION}

The healthcare industry in China has entered a new phase with rapid transformation and application of technology to its growth. Typical of most industries, digitisation of healthcare products, services and models of commerce is democratizing the current healthcare system in China while unlocking new previously inaccessible healthcare segments[1]. This monumental convergence of healthcare industry with IT is part of a larger evolution and growth of $\mathrm{E}$ Commerce from simple search portals for purchasing goods and services to more integrated digital marketplace that incorporates personalized experience and informed purchase decision making into online behaviours[2]. The result is the manifestation of a new era of healthcare consumerism, as healthcare customers equally want to be given 
retail-like buying experience. Wang et al [3] appropriately argue that E-Commerce has changed the way people shop for healthcare products and the way the product ends up in their hands. They are hesitant in personally visiting physical brick and mortar locations but instead turn to the convenience of the Internet to perform the functions of a regular pharmacy and other medical care. Unsurprisingly, ECommerce has crept into the territory of hitherto highly regulated medical care services itself [4].

The pioneering form of healthcare E-Commerce applications like Practo and FirstOpinion, and dedicated healthcare websites like Doctor2U and YourDoctors online have successfully created an ECommerce niche called telemedicine[5]. Even though the business model of each of these platforms differs slightly from each other, the underlining concept is the same (doctors offer advice over text or live chat to patients, eliminating the need for a physical doctor's office or time spent traveling away from home)[6]. ECommerce healthcare however has not eliminated the need for in-person examinations, yet telemedicine can often help patients determine whether an examination is necessary. Asante Antwi et al[7] predicted that by the end of 2020, the number of tech-savvy millennials will overtake the number of baby boomers and the preference for E-Commerce models with personalized UX/UI marketing channels for medical products and services will escalate. Asia as a whole and China in particular is home to nearly half of these millennials[8]. The Asian millennials are not only technology savvy but socialised differently from the traditional socialist lifestyle and free from ancient social mores such as sobriety, simplicity and frugality[9]. They are the offspring of wealthier elites that are willing to spend more for better healthcare for themselves and their families[7].

The current paucity in academic studies relating to ECommerce in the healthcare industry in China is blamed on the late development of this segment of E-
Commerce[19]. This notwithstanding, some significant breakthrough studies have emerged overtime.

A weakness in these studies is that most of them focus on the analysis of the key trends and developments around healthcare E-Commerce especially in North America. Some of these prior studies have equally focused on healthcare E-Commerce market projections, analysis of opportunities by supply chain participants, strategic imperatives, and selection of industry best practices while other have looked at healthcare E-Commerce-Drug and device market overview[20-22]. Yet, healthcare E-Commerce is only a means to an end (public health quality) and high economics undertone prevails in these prior studies, which deprives them of their public health importance. More recent studies suffer from similar undertones despite persistent call for future research to focus on the public health implications of healthcare E-Commerce. For example very recent studies largely focuses on pharma drug E-Commercestrategic priorities and preferred channels, the cardinal health-stepping up to support pharmacies in E-Commerce revolution[23, 24], the challenges through E-Commerce[25, 26], E-Commerce opportunity analysis by pharma drugs and therapeutic types[27, 28], healthcare digital transformation attractiveness luring new entrants[29, 30], revenue forecast by sales channel-medical device E-Commerce market [31], medical device E-Commerce and scope of process optimization and how PBM E-Commerce play-recalibrate toward value-based Healthcare[32]. These previous studies have focused largely on the economics of E-Commerce healthcare with little emphasis on the public health implications. The few studies that offer tangential exposition on public health implications of E-Commerce healthcare are mostly conducted in the western world especially in North America and what is known in China needs to be systematically synthesized through extensive review of available literature. We draw inspiration from the fact that China is the largest healthcare 
market in the world (both consumption and supply) hence inroads into public health implications of healthcare E-Commerce can offer useful insight and lesson for its nearest neighbours and many countries in the world that wants to replicate China's development model for their own socio-economic transformation. Firstly we describe our data selection process and other protocols. We then discuss findings of the study regarding the role of healthcare $\mathrm{E}$ Commerce in reconstructing the healthcare value chain. The next section explores the role of healthcare E-Commerce in reengineering hospital operations and service processes. We then summarise our findings and implications for the future of healthcare $\mathrm{E}$ Commerce.

\section{METHODS AND MATERIAL}

To achieve the objectives of this study the procedures and set of activities outlined in the Preferred Reporting Items for Systematic Reviews and MetaAnalyses (PRISMA) flow chart was used. Figure 1 shows the graphical representation of the selection activities. The PRISMA guidelines was developed in 2009 as an updated version of the QUOROM Statement (QUality Of Reporting Of Meta-analyses), that was earlier developed in 1999 by an international group to ensure systematic reporting of meta-analyses of randomized controlled trials. Since then the PRISMA model become the generally acceptable blueprint guidelines for both systematic review and meta-analysis because it quality and the transparency of the reporting process of review. Healthcare ecommerce is a multidimensional construct in practice, mechanism and processes. The field has evolved through aggregation of sophisticated intrinsic and extrinsic factors. It is dominated by many different actors whose operations are interconnected by a seamless coordinated system that forms the traditional value chain. In other words the context of healthcare ecommerce and practice, theoretical expositions and assumptions, policy and regulatory framework are shaped by a matrix of socio-cultural and economic factors that has evolved overtime. This makes health practice a dynamic and constantly and rapidly evolving endeavour for business organisations that wants to take advantage of its benefits. This has culminated in the emergence of several ecommerce platforms for both clinical and non-clinical practice. The research evaluated and synthesized how different healthcare ecommerce platforms and stakeholders are complementing health service delivery to ensure accessible healthcare in China.

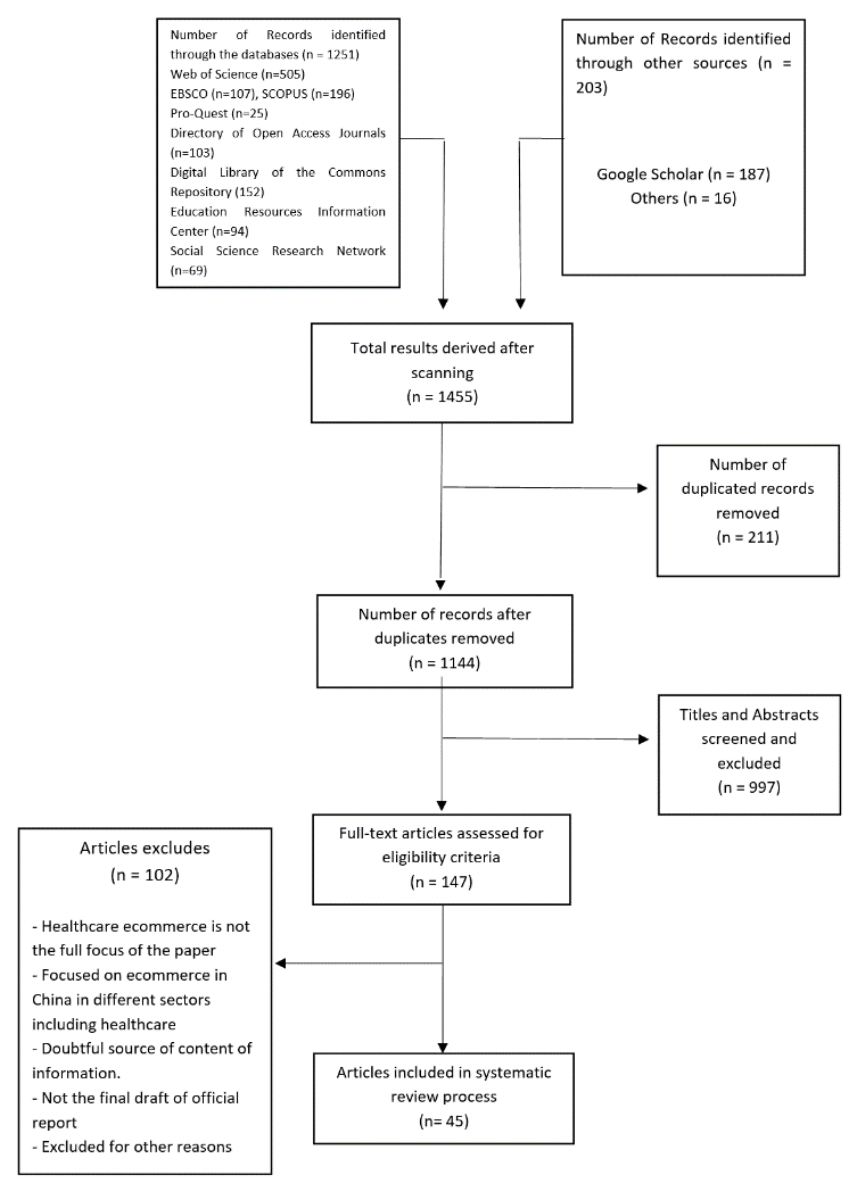

Figure 1 : PRISMA Model

\section{Search Strategy}

Between April 2019 and March 2020, an electronic search was conducted in ten academic databases namely : Science Direct, EBSCO, Directory of Open Access Journals, Web of Science, SCOPUS, Digital Library of the Commons Repository, Public Library of Science, Education Resources Information Center, 
Pro-Quest, arXiv e-Print Archive, Social Science Research Network, Information Center, Social Science Research Network. For each database, distinct and hierarchical search cluster terms were defined i.e. main topic, subtopic and specific theme. The themes include relevant studies examining the current healthcare E-Commerce from stakeholder perspective. These stakeholders include pharmaceutical manufacturers, pharmaceutical wholesalers, logistics distribution centres, medical institutions (hospitals, clinics, health centers etc), medical research institutions, financiers, pharmaceutical benefit managers (PMB), health insurance companies and government. Narrative search was used to select them.

The term "healthcare E-Commerce" encompassed "the application of communication and informationsharing technologies during the process of marketing, exchanging, servicing, buying, and selling of healthcare products, professional services, funds, and information over an electronic network, primarily by phone and Internet connectivity". It combines business and electronic infrastructure which allows traditional business transactions to be conducted electronically, ignoring the physical or geographic boundaries separating them [14]. All studies should have been published before the date of the last search (March 31, 2020). There was no discrimination on the author's location (foreign and local authorship) in so far as the article was based on E-Commerce in China's healthcare. Consistent with PRISMA requirements, the search terms were combined through Boolean operators such as AND/OR. Well trained research assistants ( $\mathrm{PhD}$ candidates) and the author entered each key subject terms individually in English.

Truncations as well as wildcard characters helped to improve the sensitivity and precision of the searches. The initial searches did not discriminate in terms of publication time frame, research design (qualitative/quantitative research, primary/secondary research), peer review criteria (essay or dissertation or academic paper). This initial search yielded 1251 articles as indicated in the PRISMA flow chart in figure 1. Google Scholar, Sage (open access) article references, relevant reviews and book chapters were further searched for additional relevant publications to identify original research studies exploring how ECommerce is complementing the traditional healthcare delivery system in China for the period 2010 to 2019. Through this process 203 additional articles were retrieved and added to the selection process.

\section{Screening}

The articles were initially screened to remove duplicates in a two-step process. The entire list of articles was imported to four citation manager namely Mendeley, EndNote, Sciwheel, and Zotero. Four welltrained research assistants with expertise in library and archival reference management information system removed all duplications. The screened results from each of the four citation managers were carefully compared. After manually inspecting and validating the articles, the author compiled the final list of qualified articles. From this process, a total of 211 duplicate articles were removed from the list of 1455 articles leaving a total of 1144 qualifying articles. These final articles were further validated by the author and the research assistants

\section{Eligibility}

A strict eligibility criterion was used to determine qualifying articles for the final review. Firstly, the article should be available in English language. Secondly, the article must focus on healthcare ecommerce issues in China. Thirdly, the article should be a peer reviewed academic paper and where it is not the case then it must be a document from a highly rated, international or recognised professional group. Another selection criterion is that the article must be related to digital healthcare that talks about China, China-US, China-Canada, China-UK, ChinaJapan, China-Australia. These countries were selected due to their advanced use of digital healthcare systems. Whether articles were included for full-text analysis was determined by the author with the 
assistance of trained literature search specialists depending on whether the articles fitted well with the eligibility criteria.

A total of 997 records were excluded in this stage of study selection. Third, from the remaining 147 records, full text articles were assessed independently, for the final selection of eligible studies. Again disagreement/discrepancies were resolved by consensus. The key selection criteria were that the article must be based on official data from highly recognised institutions. After this round, 102 records did not meet the inclusion criteria and were excluded from further analysis, leaving 45 studies eligible for inclusion.

\section{Extraction and Analysis}

The author with the support of the research assistants independently extracted data from the 45 studies using a standardised data extraction form. The following data were extracted: author and year of publication, study population, location of the study, primary study aim, type of study (either quantitative or qualitative) and the approach of study. The author and highly trained research assistants reviewed studies independently. In the first stage, the author developed a framework of concepts and themes, based on study data and pertinent discussion points. In the second and last stage, the remaining other authors independently reviewed the studies, developed this framework and further reviewed the concepts and themes to ensure the face validity.

All qualitative and quantitative studies reporting the application of communication and informationsharing technologies during the process of marketing, exchanging, servicing, buying, and selling of healthcare products, professional services, funds, and information over an electronic network, primarily by phone and Internet connectivity were included in the analysis. The qualitative studies were analysed using thematic analysis (Braun \& Clarke, 2006) for identifying and analysing patterns (themes) in qualitative data. Initially, after all healthcare ECommerce utilisation papers were extracted; the authors searched for patterns of meaning in these papers, grouped them according to content and gave them working titles. This grouping process was constantly supervised by the supervising Professor, (LZ) and any disagreements were solved by discussion among researchers.

The collated e-Commerce interventions were refined and the working titles were adjusted to the final names of the key themes. In the end, included quantitative studies used a survey method to gather relevant information regarding healthcare ECommerce utilisation. For each study, results were extracted based on the following questions: (1) how E-Commerce is helping to reconstruct the healthcare value chain (2) how E-Commerce is reengineering hospital operations and service processes (3) What are the challenges of E-Commerce intervention in Healthcare in China (4) What are the prospects of the future of E-Commerce intervention in healthcare in China. The results are reported in a thematic analysis because of the heterogeneity of the studies with regard to study population, research setting, analysis, design, and type of research.

Table 1 : Summary of Final list of Healthcare Ecommerce related studies selected for discussion

\section{Thematic}

Areas

\begin{tabular}{lcccc}
\hline Databases & $(1)$ & $(2)$ & $(3)$ & $(4)$ \\
\hline Web of Science & 7 & 6 & 5 & 3 \\
SCOPUS & 3 & 2 & 1 & 0
\end{tabular}




\begin{tabular}{lllll} 
EBSCO & 4 & 3 & 2 & 0 \\
Pro-Quest & 3 & 2 & 1 & 0 \\
$\begin{array}{l}\text { Directory of Open Access Journals } \\
\text { Digital Library of the Commons }\end{array}$ & 4 & 3 & 2 & 0 \\
$\begin{array}{l}\text { Repository } \\
\text { Education Resources Information }\end{array}$ & 2 & 1 & 0 & 0 \\
Center & 5 & 4 & 3 & 0 \\
Social Science Research Network & 5 & 4 & 3 & 1 \\
Public Library of Science & 4 & 3 & 2 & 0 \\
arXiv e-Print Archive & 3 & 2 & 1 & 0 \\
Social Science Research Network & 2 & 1 & 0 & 0 \\
Google Scholar & 1 & 0 & 1 & 0 \\
Others & 2 & 1 & 0 & 0 \\
\hline & 45 & 32 & 20 & 17
\end{tabular}

The information in table 1 provides a summary of the final list of accepted articles for the discussions and the areas of the research they convert based on the four thematic areas stated earlier in this section of the study. Off the 45 articles that were selected, all of them had issues that relates to the first thematic areas which is how E-Commerce is helping to reconstruct the healthcare value chain (1). 32 of the articles also had materials on the second thematic area that relates to how E-Commerce is reengineering hospital operations and service processes (2) while 20 of the articles had materials relating to what the challenges of E-Commerce intervention in Healthcare in China are. Finally, 17 of the articles also had issues that dealt with what the prospects of the future of E-Commerce intervention in healthcare in China (4). Thus even though only 45 articles were finally selected, they had multiple issues of relevance to the research objectives to examine hence their inclusion for analysis.

\section{ANALYSIS OF RESULTS}

\section{Evolution of Healthcare E-Commerce}

The digital transformation of healthcare was championed by the United States due to access to the core computer and Internet technology and a highly participative healthcare consumer market [15]. Until recently, North America championed the growth of the E-Commerce for health industry the world over. It was projected that the E-Commerce for medical devices and pharma drugs will exceed $\$ 200$ billion by 2022 in North America.

E-commerce healthcare in the U.S. is driven by an agency's interest in reducing costs and improving patient engagement. Since then, investment in medicines has increased, regulatory conditions have improved, interaction between payers and digital instruments has improved, and telemedicine has been improved through integration. The digital health industry is built on major events of recent years. In the early part of 2018, Amazon made headlines announced a partnership with Berkshire Hathaway and JPMorgan Chase to create a new entity to improve care options for its employees and this was a major breakthrough in digital healthcare development. Amazon has also expanded its software to digitize and tap patient records to improve treatment and reduce costs. It joins IBM and Optum in a joint healthcare company, as well as Apple and Google's efforts to mobilize, organize, and analyze medical records. The buyer of these services is health 
systems, which have historically lagged far behind the potential of electronic analytical records. Investing in pharmaceuticals is another important area for the healthy development of U.S. digital. Hassan [21] explains that pharmaceuticals finally embrace digital with the creation of dedicated C-suite positions to manage it. Shortly thereafter, Pfizer announced that Lydia Fonseca would become chief digital and technology specialist, and Merck named Jim Sholfield as Chief Information and Digital Specialist. Novartis appointed Bertrand Bodson as Chief Digital Officer [18]. These bellwether hires join the ranks of people such as Karenanna Terrell, Chief Digital and Technology Director of GSK, who represent a new class of digital executives in leading pharmaceutical companies. Further leaders of Pharma and America are seeking to create influence and make deals. Examples of companies that have already established partnerships are Pear Therapeutics with Sandoz and Digital Therapy, as well as Proteus Digital Health with Otsuka Pharmaceutical and Digital Tracking Medicine. Science 37 has received significant investment for virtual clinical trials. The New Year should see the continuation of partnerships and research and development and therapy. In terms of regulatory availability, the U.S. Food and Drug Administration (FDA) has cautiously shifted to the use of digital therapeutics, mobile testing platforms and extended use of real world records (RWE) Mining for clinical development. This progress continues to drive investor interest. In 2018, the FDA issued a statement calling for efforts to promote innovation and digital healthcare [20]. It supports a new technological paradigm of digital healthcare tools, as it allows consumers and suppliers to replace traditional, physical limitations of care. The list of companies with digital products in development who have been approved in the US is growing. Substantively, the agency has issued landmark approvals of digital products including Pear's reSET, Proteus/Otsuka's Abilify MyCite, and earlier WellDoc's BlueStar. Click Therapeutics is working with Otsuka on a digital approach to severe depression, Dthera Sciences is developing a product for Alzheimer's disease and Akili Interactive in trials to treat pediatric ADHD. Regulators are working with industry and academia through advisory partnerships such as the Clinical Trial Transformation Initiative (CTTI), which actively makes recommendations in areas such as mobile RWE technology and usage [21]. It's been more than a year since the FDA published its Digital Health Action Plan to develop a precertification program that will reduce the need for standard authorization requirements for certain types software and applications. Further modernization of the digital regulatory pathway and framework for the use of artificial intelligence (AI), digital safety reporting and RWE in clinical development is expected. Another area of health care digitization in the states is attracting payers. Health insurers in the U.S. are committed to improving customer engagement and building loyalty with new digital tools as they continue to explore value health care. Payers are working to control costs and expand their footprint through mergers such as Aetna with CVS or Cigna with Express Scripts, and these activities will be balanced by efforts to build closer relationships with customers. The industry invests in AI directly or through relationships with new firms [22]. Optum Ventures of UnitedHealth Group is an investor in Buoy Health, which offers a gateway for treatment using a chatbot described as a digital health assistant powered by AI. Anthem is working with Doc.ai to help empower consumers who use digital interaction tools, such as healthy forecasts around lifestyle, environment, and activities.

As stated earlier, until recently, North America championed the growth of the E-Commerce for health industry the world over. It was projected that the E-Commerce for medical devices and pharma drugs will exceed $\$ 200$ billion by 2022 in North America but the growth in China will overtake this figure in 2020[10]. This will represent a compound annual growth rate (CAGR) between of $10 \%$ to $15 \%$. 
This escalated E-Commerce for health story is playing out in response to increasing healthcare awareness and expenditure in Asia [24]. At the same time rising incomes makes it attractive for companies to invest in this sector to benefit from persistent economic growth that has created first generation wealthy families that wants accessible and convenience healthcare[11]. Furthermore, because healthcare has become an important investment theme in China and other Asian countries with increasing ageing population [12]. Governments have intensified efforts to construct the social safety nets needed to reduce excessive reliance on healthcare exports and boost domestic consumer demand. In 2018 CLSA AsiaPacific Markets reported that a major part of China's E-Commerce for healthcare sector appeal is largely because it has a lot of companies that produces drugs and medical devices that are well-positioned to tap the burgeoning domestic and global market[8]. Additionally, China has announced ambitious reforms to provide $95 \%$ of the population with health insurance and spend $\$ 125 \mathrm{~b}$ ( $¥ 850 \mathrm{~b}$ ) on health-care improvements between 2015 and 2020 to stimulate demand in biopharmaceuticals and medical devices [14]. China also seeks to drive $25 \%$ revenue growth in China's pharmaceutical industry over the next two years[13]. Unlike other sectors such as banking, telecommunications etc the state-exert limited dominance in the healthcare markets especially the market for drug production and medical-devices in China and this is making it easier for private-sector companies to make a mark.

In their seminal work, Frost and Sullivan defined healthcare electronic commerce (E-Commerce) as "the application of communication and informationsharing technologies during the process of marketing, exchanging, servicing, buying, and selling of healthcare products, professional services, funds, and information over an electronic network, primarily by phone and internet connectivity. It combines business and electronic infrastructure which allows traditional business transactions to be conducted electronically, ignoring the physical or geographic boundaries separating them"[14].

$\mathrm{Li}$ et al [10] explains that healthcare E-Commerce is not a software or an IT platform feature but an integrated part of an evolving ecosystems that has digitally led to the infusion of emerging business models such as servicization, amazonization, uberization, and shared-economy among others into the management of public healthcare services. They further explain that the adoption of healthcare ecommerce is fuelled by trends in both demand side factors (cost and pricing pressures) and supply side factors such as health consumerization. Beyond there is also the issue of increased competition by digital healthcare market participants (e.g., Amazon, Ali Health, Apple, and so on) which were non-existent a few years ago [15]. Companies like Capsule use a business model that features fast delivery to patients' doors, live online chats to handle patient questions, and an app that allows doctors to order directly through Capsule. In 2017, Capsule raised \$20 million from investors who bought into its business model, despite the fact that similarly structured competitors PillPack, ScriptAssist, DivvyDOSE, and others were already active in the market[16]. In 2018, PillPack was acquired by Amazon for just under $\$ 1$ billion, again demonstrating the confidence that the market has in this shifting healthcare landscape.

The interplay between these forces has shifted the paradigm of the health care market [19]. Drugs devices, original equipment manufacturers, wholesalers, GPOs, PBM distributors and retailers have all been compelled into digital platform to leverage on E-Commerce in order to achieve efficient operation, standardized purchasing processes, optimize supply chain inefficiencies and improve end-user experiences[17]. Due to digital market place scalability, drug/device companies are able to differentiate with value added services such as same day delivery, free shipping online payment, discounts, customer feedback on service, product quality certification and more importantly the ability to 
connect with customers on a 24/7 which lengthens customer engagement and relationship while improving overall transaction experience[18].

\section{E-Commerce is Reconstructing the Healthcare Value Chain}

Detail analysis of the available literature suggests that an important area that E-Commerce in healthcare is making influential inroads in public health is the reconstruction of the pharmaceutical value chain. Healthcare depends on the development and effective distribution of high quality and affordable drugs to patients[33]. The pharmaceutical value consists of all the set of activities including the design, production, marketing and distribution of pharmaceutical products and services. In China as in many other countries, the pharmaceutical industry is a multisystem made up of primary subsystems including inbound logistics [34], operations, outbound logistics, marketing and sales and after sales services [34]. It involves a litany of different actors that must work in harmony like an orchestra to maintain the stability of the pharmaceutical value chain[35]. Some of these actors include pharmaceutical manufacturers, pharmaceutical wholesalers, logistics distribution centres, medical institutions (hospitals, clinics, health centers etc), medical research institutions, financiers, pharmaceutical benefit managers (PMB), health insurance companies and government. Currently, hospital terminals are the major point of sale for most pharmaceutical products in China[36]. The dangers of the fake drug market and other healthcare consequences of drug consumption are responsible for this highly regulated drug delivery and dispensary system in China.

Moreover, pharmaceutical manufacturing companies in China barely have any self-managed independent distribution channels due to retail market complexities. For this reason the drug delivery in China goes through an 'iron cast' multi-layered links before it reaches the final consumer. This syndrome reduces the circulation efficiency as it is embedded with artificially hiked prices because of the rebates and commissions charged frequently by the different layers of intermediaries. In other words, for decades, pharmaceutical wholesalers in China have constituted an entire industry and served as the middlemen between manufacturers and consumers[37]. They purchase items in bulk from the pharamceutical companies at a set price, then sell it to consumers at a higher price, often doubling or tripling their output. Despite public disapproval of this business model drug manufacturing companies in China, continued this model for years since it was the cheapest way for them to get their products to customers[38]. Wholesalers rather provided the manpower, infrastructure and retail space that the manufacturers could not easily afford on their own. This resulted in constant increases in the selling cost to pharmaceutical companies as the drugs travelled through the value chain to the final consumer. This phenomenon was exacerbated by the policy of markup percentage control that allowed hospitals to get more profit on the drugs they sell if they sell them at higher prices to the detriment of patients. Xi et al [39] interrogates this phenomenon and assert that hospitals typically cover expenses with revenue from medicine and that exerts pressure on the profit of drugstores. At the end of the value chain, patients find themselves in an unfavourably passive position, facing sky-high drug prices. This explains why hospitals prefer to sell highly priced drugs in order to improve their income. The catastrophic public health effect of the phenomenon of highly priced pharmaceutical products and patients struggle to access basic and less expensive drugs is well documented in [40-43].

However, with time, healthcare E-Commerce is gradually reconstructing the pharmaceutical value chain by compressing the intermediaries and making drug selection and prices more demand driven, market oriented and transparent[44]. With ECommerce, manufacturers are increasingly skipping 
wholesalers' altogether and are selling products directly to their consumers via the Internet. These drugs are even delivered to the doors of consumers at far lower cost than through intermediaries[45]. Traditional wholesalers and retailers, such as big-box stores, malls and other brick and mortar shops, have become increasingly concerned. They are faced with unprecedented competition from online shops, often at prices they cannot match without losing money. Gong et al [46] reports that different pharmaceutical companies are experiencing the impact of healthcare E-Commerce in different ways but sums up to the same problem. Since patients can use Internet platforms to identify and select the most cost effective drugs, they can easily identify which generic pharmaceutical manufacturer offers them the desirable products and services. Thus E-Commerce has enabled the generic pharmaceutical manufactures with historically weak sales force to expand their market share.

Secondly newly added internal channels allow the large pharmaceutical companies to improve liquidity flow. They are able to push up sales for exclusive drug varieties in order to retain its price advantages. The advantage of these supply side opportunities is a motivated producer base to guarantee the availability of healthcare resources for uninterrupted public health delivery [47]. The public health benefits are even more enormous on the demand side as the purchasing power of patients has increased through E-Commerce for health. With E-Commerce, drug prices are becoming more transparent and drug terminal prices have reduced and customers buy drugs at more affordable prices. Moreover, effective management of mobile medication management has contributed to quick and efficient buying process[48]. This is very important for disease prevention since the share of preventive health expenditure to GDP is nearly $0.44 \%$ in China. The data produced by pharmaceutical E-Commerce is not only useful for drug administration purposes but covers the overall health industry. Pharmaceutical E-Commerce transactions are being used to establish user health files, integrate the information, store them in the "cloud" and use them to provide clients with medication guidance and other value-added services[49].

This is stimulating new frontiers in healthcare information innovation[50]. For example, pharmaceutical manufacturers are using E-Commerce data to analyse drug flow, sales volume, etc. Due to enhanced drug production standards across the globe, more transparent pharmaceutical industry data are available to medical institutions and production enterprises to improve their products and services. Beside the demand for easy-to-use pharmaceutical ECommerce platform[51], the future growth challenge that now faces pharmaceutical companies on ECommerce platform is the development and sustenance of seamless demand-side and supply-side relationship to improve positive customer experience. The other demands of customers are affordable price, quick pickup, high-quality service, diversified drugs and brand trust[52]. These key drivers are conditional imperatives for pharmaceutical enterprises to establish and improve appropriate internal capabilities to enhance the E-Commerce transaction flow[49]. This will also enable these enterprises to convert passive consumers into active customers. The overall effect of these breakthroughs on public health is greater access to affordable, timely, quality healthcare as a results of transforming the supply chain and organisational value chain process through which drugs get to the rightful persons who need them[53].

\section{E-Commerce is Reengineering Hospital Operations and Service Processes}

The second important area where E-Commerce is supporting public healthcare is the need to reengineer hospital operations and service processes. An important aspect of E-Commerce intervention in this regard is the extensive application and integration of 
mobile internet technologies into traditional medical systems[54]. This integration has injected new vigour into healthcare delivery in China as hospitals have responded by developing new management information systems that are operationally compatible with emerging technology which broadens the frontiers of health service delivery[55]. In some provinces such as Beijing, Shanghai, Chongqing, Guangdong, Zhejiang and Jiangsu, there is state sponsored effort to provide single spine digital healthcare platforms that integrate the operations of groups of hospitals in seamless collaborative network of healthcare institutions to promote medical interinstitutional relations[56].

This is because mobile internet enables hitherto autonomous institutions to break through time, space and geographic restrictions to facilitate hospital information sharing, resource allocation and transfer[57]. In addition, digital transformation is supporting process re-engineering of existing hospital operating models and services by helping to transfer unique and scarce resources available in highly placed medical facilities to less endowed healthcare facilities to leverage shortfalls[58]. The preamble of the Healthy China 2030 Agenda embraces this advantage by calling on hospitals and policy makers to agree that integrating mobile internet technology into hospital information systems can ensure access to complete, correct, timely, relevant information, speeds up intrafacility and inter-facility information sharing and enhance patient-doctor interaction[59]. The public health benefits include avoidance of complications resulting from patients' lack of information about symptoms and diseases and this can reduce late diagnosis, complications and quicken up emergency services[60]. In addition, hospital staff will have enough time to prepare in anticipation as they become more apparent through remote monitoring. Further, the digital transformation is placing routine administrative processes of Chinese hospitals online to free up medical staff to concentrate on the critical areas of patient care[61]. This is important because patient satisfaction is the ultimate goal of all healthcare decisions. Moreover digitalisation of healthcare allows physicians to access and draw on patient information (including image archiving, blood samples, etc.) at any time, receive early warnings about diseases and track patient's rehabilitation status after hospital discharge[16]. This is the concept of after sales services; an offshoot of traditional customer services which modern healthcare customers expect of hospitals in China. Further access to the same information online allow team of doctors to share patient information in real time, encourage cooperation and reduce the probability of misunderstandings in healthcare data[62]. Through prescription evaluation system and aided diagnosis system being championed by digital healthcare, Chinese hospitals can improve diagnosis and treatment, and control expenses[63]. Most of China's medical resources are concentrated in its public hospitals limiting the amount of healthcare resources available for general healthcare and outpatient rehabilitation among others. Internet intervention in healthcare has expanded overall medical services as online medical services suppress the entrenched 'gang' of intermediaries. In that regard, patients, meanwhile, are using mobile internet technology to view their medical history, complete registration, treatment, and claims forms, among other activities[48]. In China, "ChunyuDoctor" (Chunyuyisheng) is the pioneer in this industry. Since 2011 it has provided its users with self-examination enquiry services function and has a total active user population of nearly 125 million and 500,000 registered medical practitioners. Chunyu and many similar resources have gained popularity among ordinary folks because it satisfies patient's low level medical services demands and this saves time and eases the pressure on shortage of authentic medical resources[64]. With Chunyu Doctor, patients can make online doctor appointment using their mobile phones and this can be done in both second and third tier hospitals. The platform allow patients to directly communicate with the doctor through text messages, 
voice-based phone calls over the internet, and transfer of data files[65]. The platform also offer multiple practice areas for the diverse needs of its clients and these include maternity, family practice and pediatrics[65]. Chunyu Doctor has empowered patients to ask questions directly to doctors in second and third tier hospitals and receive answers within three minutes[66].

In essence the internet market for healthcare is largely filling the gap and satisfying the ignored market niche which traditional healthcare system has failed to support. Baidu currently operates what it calls the "Medical Brain" project. This project combines big data, machine learning, artificial intelligence and other emerging technologies that is assisting doctors to develop diagnosis and treatment schemes[67]. Since its inception the Baidu Brain is credited with automatic diagnosis of very rare skin diseases and is currently navigating more complicated medical fields[68]. Besides Alibaba's Future Hospital Plan is preparing to fully open up its platform to medical institutions to help hospitals set up mobile healthcare systems[69]. The plan also seeks to assist patients complete their registration, report pickup, and make payment and interact with doctors after diagnosis using the Alipay Wallet. Currently 50 thirdgrade Class A hospitals nationwide are piloting this concept[33]. The Tencent Intelligent Medical Program is another breakthrough in healthcare ECommerce as it seeks to set up a hospital in a pocket. With this application, patients can register pay fees check health records and laboratory reports on Wechat public forum[70]. In November 2014, Tencent partnered the Guangzhou Municipality's Bureau of Health to "Guangzhou Health Bestone" using their WeChat public number. Till date 60 Guangzhou hospitals have participated and Guangdong residents were the first to enjoy this high level convenient e-healthcare system.

\section{CONCLUSION AND RECOMMENDATION}

Two decades ago the outpatients' medical doctor in a Chinese hospital treated around $60-70$ patients in a single day because of scarce medical resources. Currently, this number has doubled and nearly 120 patients visit a single medical doctor's consulting room in Urumqi, Zhenjiang, Xian, Hefei, Nanning, Kunming, Nanchang etc every day. The situation is worse in major cities such as Shanghai, Beijing, Nanjing, Guangzhou, Shenzhen, Hangzhou, Suzhou, etc. This monstrous workload on a single doctor requires fundamental upgrade in hospital operation mechanisms to support and improve the doctor's work efficiency. This is where technological intervention is providing enormous support. Without technological transformation of the medical processes, highly compromised medical care that is at variance with the Healthy China 2030 agenda will become endemic even in major cities with better healthcare resources. Technological intervention in healthcare is the only panacea to achieving convenient and comfortable medical services for the ever-growing number of patients.

For example the great value of mobile internet technology for healthcare is that mobile internet technology helps to better understand complex patient information and status before and after the operation at any place and time. It also allows for healthcare practitioners to make full use of fragmented information and time to choose the best operation qualifying process, eliminate waste and waiting time in instances where the information is not well networked. This improves work efficiency as patches are systematically assembled to help medical practitioners map out more clearly patients' past history of illness, keep the diagnosis and treatment quicker, comprehensive and safer. Thus the rise of healthcare E-Commerce has rejuvenated the healthcare industry creating opportunities to expand the overall medical service. Currently healthcare E- 
Commerce offering has covered most of the existing niches or sectors in the healthcare industry such as pharmaceutical and health equipment supply chain, medical treatment, outpatient hospital services, selfdiagnosis, post-diagnosis monitoring, health management, hospital guidance and rehabilitation assistance among others. Chinese enterprises have created their own version of Pocket Check-Up, Meet You health management; Go to Hospital, HaoDF for hospital guidance, Dnurse, and I Health BPM for rehabilitation monitoring and these are gaining momentum. That notwithstanding, there is still the prospect of creating new niches for healthcare innovators to benefit while providing patients and other actors with high quality assurance. Technology is not static and with time new opportunities and niches must be created for the reciprocal benefit of innovators and patients. Through medical ECommerce services, hospitals and patients can now break through hospital and regional barriers to identify doctors with needed skills for specific cases. Further, hospitals have the opportunity to organise medical teams for patients by consulting information shared by experienced physicians in the emerging "Medical ideas Banks" to satisfy multilevel medical demands (from minor diagnoses to severe cases). This notwithstanding, there is the need to better prepare healthcare consumers on the correct usage of these electronic resources especially those which require a greater level of "Do it Yourself" (DIY). Further, healthcare policy makers and managers must understand that there is no one-size-fit all health ECommerce strategy when it comes to healthcare products and services. Those within the supply chain system (drugs and health equipment manufacturing and supply) need to focus on the E-Commerce strategy that accommodates the level of maturity of their buyers. This may require them to use a suitable mix of available digital tools to educate, research on product information, order management, and payment and reimbursement systems.
In addition, imparting technological advances in healthcare to aging population in China can be challenging. Aging population has moved a significant number of healthcare consumers upstream with less interest in complex technologies. Compatibility and simplicity must be the defining "word" in the next generation of technological interventions in healthcare if they can make any impact. China has been at this intersection before as Alipay and Wechat software technologies have been leveraged by both the elderly and younger generations for their benefits. This success must inspire China to identify the password to decoding the "aging populationtechnology adoption" puzzle.

Like most sectors, E-Commerce laws in China are still at the elementary stage and even where they exist, consumers have limited knowledge of their rights and responsibilities. We call for an unprecedented, urgent and concerted effort to address this potential pitfall in the success of E-Commerce application in healthcare in China. This same effort must be directed to arrest the effect of the huge E-Commerce-driven fake drug market in China and prevent it from suppurating.

\section{DECLARATIONS}

\section{Ethics approval and consent to participate}

Not applicable

\section{Consent for Publication}

Not Applicable.

\section{Availability of Data and Materials}

Not Applicable

\section{Competing Interest}

Not Applicable

\section{Funding}

The National Natural Science Foundation of China (71904066), the Social science application research project of Jiangsu Province (19SYB-095) and the Universities'

Philosophy and Social Science Researches in Jiangsu P rovince (2019SJA1884) provided assistance for 
expenses incurred in the recruitment and training of research assistants, expenses incurred in accessing closed-access journals, proof reading services and cost of publication of final manuscript.

\section{Acknowledgements}

The support of colleagues and staff at the Department of Public Management of the School of Management, and the Centre for Health and Public Policy Research is deeply appreciated

\section{REFERENCES}

[1]. X. Zhu, "China's Technology Innovators," Management for Professionals, 2018.

[2]. R. Thiebaut, "AI Revolution: How Data Can Identify and Shape Consumer Behavior in ECommerce," in Entrepreneurship and Development in the 21st Century, ed: Emerald Publishing Limited, 2019, pp. 191-229.

[3]. X. Wang, H. Yu, and S. Yu, "Analysis on the Status Quo of Health Food Purchase for Overseas Tourists in China," in 2018 International Workshop on Education Reform and Social Sciences (ERSS 2018), 2019.

[4]. X. Zhu, "Case V: 3DMed: Digital TechnologyNavigating Precision Medicine Towards Success," in Emerging Champions in the Digital Economy, ed: Springer, 2019, pp. 161-194.

[5]. A. L. Foster, "COMPETITION LAW AND PHARMA: CHINA," in EU LAW OF COMPETITION AND TRADE IN THE PHARMACEUTICAL SECTOR, ed: Edward Elgar Publishing, 2019.

[6]. X. Chen, "The Current Status and Development Countermeasures of Online Pharmacies in China," Open Journal of Social Sciences, vol. 6, p. 224, 2018.

[7]. H. A. Antwi, Z. Lulin, E. A. Antwi, B. Kusi, T. Mustafa, and Z. Abdullai, "Deciding with the Crowd Wisdom: An Overview of Issues Facing the Corporate Application of Prediction Markets," 2017.

[8]. L. Zhao, Q. Liu, and Y. Wang, "Development status and suggestions for e-commerce platform of traditional Chinese medicine in Henan Province," in IOP Conference Series: Earth and Environmental Science, 2019, p. 012038.

[9]. A. Sethi, "Digital China," in Chinese Consumers, ed: Springer, 2019, pp. 33-54.

[10]. C. Li and Z. Huang, "Evolutionary Game Analysis of Online and Offline Drug Retailer Competition Based on Network Externalities," IEEE Access, vol. 7, pp. 96620-96627, 2019.

[11]. Z. Lulin, E. Yiranbon, and H. Asante Antwi, "Complementarity of clinician judgment and evidence based models in medical decision making: antecedents, prospects, and challenges," BioMed research international, vol. 2016, 2016.

[12]. D. He, W. Zhang, G. Han, and T. Wu, "Productivity Growth of the Nontradable Sectors in China," Review of Development Economics, vol. 18, pp. 655-666, 2014.

[13]. X. Xu, L. Zhou, H. A. Antwi, and X. Chen, "Evaluation of health resource utilization efficiency in community health centers of Jiangsu Province, China," Human resources for health, vol. 16, p. 13, 2018.

[14]. X. Zhang, X. Yan, X. Cao, Y. Sun, H. Chen, and J. She, "The role of perceived e-health literacy in users' continuance intention to use mobile healthcare applications: an exploratory empirical study in China," Information Technology for Development, vol. 24, pp. 198223, 2018.

[15]. G. M. Nayyar, J. G. Breman, T. K. Mackey, J. P. Clark, M. Hajjou, M. Littrell, et al., "Falsified and substandard drugs: Stopping the pandemic," The American journal of tropical medicine and hygiene, vol. 100, pp. 1058-1065, 2019.

[16]. E. Hwang, X. Guo, Y. Tan, and Y. Dang, "Mobilizing Healthcare across Geography 
through Telemedicine Consultations," in ICIS, 2018.

[17]. P. T. Whitacre, E. Kameyama, F. CarreroMartínez, E. National Academies of Sciences, and Medicine, "Impact of E-Commerce, New Tools, Policies, and Measures," in Reducing Impacts of Food Loss and Waste: Proceedings of a Workshop, 2019.

[18]. C. Cambini, A. Giusti, and M. Faccini, "Innovazione digitale e Cross-border ecommerce in Cina Digital innovation and Crossborder e-commerce in China," 2018.

[19]. H. Yingfeng, "" Internet Plus" medical services based on total quality management theory: an empirical research in public hospital outpatient services in Guangzhou, China," 2018.

[20]. P. Xiao, "Legislative Development of Food ECommerce Regulation in China and Its Challenges," Eur. Food \& Feed L. Rev., vol. 13, p. 313, 2018.

[21]. F. Hao, D.-S. Park, X. Yin, X. Wang, and V. Phonexay, "A location-sensitive over-thecounter medicines recommender based on tensor decomposition," The Journal of Supercomputing, vol. 75, pp. 1953-1970, 2019.

[22]. X. Wu, "" Medical+ internet" concept stock investment analysis," 2018.

[23]. H. Lin, D. Xiao, Z. Liu, Q. Shi, P. Hajek, and C. Wang, "National survey of smoking cessation provision in China," Tobacco Induced Diseases, vol. 17, 2019.

[24]. J. Cunliffe, D. Décary-Hêtu, and T. A. Pollak, "Nonmedical prescription psychiatric drug use and the darknet: A cryptomarket analysis," International Journal of Drug Policy, 2019.

[25]. B. J. Venhuis, A. E. Oostlander, D. Di Giorgio, R. Mosimann, and I. du Plessis, "Oncology drugs in the crosshairs of pharmaceutical crime," The Lancet Oncology, vol. 19, pp. e209-e217, 2018.

[26]. J. Sun and J. Buijs, "Online Food Regulation in China," Eur. Food \& Feed L. Rev., vol. 13, p. 503, 2018.
[27]. L. Hu, Z. Yu, Q. Yuan, Y. Hu, and C. O. L. Ung, "Opportunities and Challenges of Multinational Pharmaceutical Enterprises in Transforming Pharmaceutical Market in China," Therapeutic innovation \& regulatory science, vol. 53, pp. 207-214, 2019.

[28]. G. Z. Jin, "Price and Quality of Prescription Drugs," NBER Reporter, vol. 2018, p. 12, 2018.

[29]. B. Niu, J. Wang, C. K. Lee, and L. Chen, "'Product+ logistics" bundling sale and codelivery in cross-border e-commerce," Electronic Commerce Research, pp. 1-27, 2019.

[30]. Y. Hu and B. Xu, "The Research of the Each Other Support between Online Sales and Offline Store based on the Marketing Mix," in 1st International Conference on Business, Economics, Management Science (BEMS 2019), 2019.

[31]. Z. Qinghua, S. Wang, Y. Zhang, and K. He, "Research on supervision system of prescription drug e-commerce," in 2018 13th IEEE Conference on Industrial Electronics and Applications (ICIEA), 2018, pp. 411-416.

[32]. J. Xu and P. Wu, "Research on the Current Situation and Strategy of E-commerce Development of Chinese Medicinal Materials in Gansu Province," in MATEC Web of Conferences, 2018, p. 05014.

[33]. Z. Tao, Z. Yao, H. Kong, F. Duan, and G. Li, "Spatial accessibility to healthcare services in Shenzhen, China: improving the multi-modal two-step floating catchment area method by estimating travel time via online map APIs," BMC health services research, vol. 18, p. 345, 2018.

[34]. R. Limaye, L. Kumar, and N. Limaye, "Fourth generation technologies in pharmaceuticalsRevolutionizing healthcare," Journal of Systems Biology \& Proteome Research, vol. 2, 2018.

[35]. K. Y. Wang and T. L. Yip, "Cold-chain systems in China and value-chain analysis," in Finance and risk management for international logistics 
and the supply chain, ed: Elsevier, 2018, pp. 217-241.

[36]. J. Huang, "Contract Research Organizations Are Seeking Transformation in the Pharmaceutical Value Chain," ed: ACS Publications, 2019.

[37]. J. Shi, D. Yi, and J. Kuang, "Pharmaceutical Supply Chain Management System with Integration of IoT and Blockchain Technology," in International Conference on Smart Blockchain, 2019, pp. 97-108.

[38]. X. Chen, H. Yang, and X. Wang, "Effects of price cap regulation on the pharmaceutical supply chain," Journal of Business Research, vol. 97, pp. 281-290, 2019.

[39]. X. Xi, Y. Huang, Q. Lu, C. O. L. Ung, and H. Hu, "Community pharmacists' opinions and practice of pharmaceutical care at chain pharmacy and independent pharmacy in China," International journal of clinical pharmacy, vol. 41, pp. 478487, 2019.

[40]. J.-Z. Wu and Y.-C. Hsu, "Decision analysis on entering the China pharmaceutical market: Perspectives from Taiwanese companies," Computers \& Industrial Engineering, vol. 125, pp. 751-763, 2018.

[41]. L. Zhang, Y. Guo, and G. Sun, "How patent signals affect venture capital: The evidence of bio-pharmaceutical start-ups in China," Technological Forecasting and Social Change, vol. 145, pp. 93-104, 2019.

[42]. M. Zhang, J. Zhang, T. Cheng, G. Hua, X. Yan, and Y. Liu, "The effect of unannounced inspection on prevention of drug fraud," Journal of Systems Science and Systems Engineering, vol. 28, pp. 63-90, 2019.

[43]. Y. He, G. Dou, Q. Huang, X. Zhang, Y. Ye, M. Qian, et al., "Does the leading pharmaceutical reform in China really solve the issue of overly expensive healthcare services? Evidence from an empirical study," PloS one, vol. 13, p. e0190320, 2018.
[44]. Z. Li, Q. Feng, J. A. Kabba, C. Yang, J. Chang, M. Jiang, et al., "Prices, availability and affordability of insulin products: a crosssectional survey in Shaanxi Province, western China," Tropical Medicine \& International Health, vol. 24, pp. 43-52, 2019.

[45]. D. Hipgrave and Y. Mu, "Health System in China," Health Services Evaluation, pp. 779807, 2019.

[46]. S. Gong, H. Cai, Y. Ding, W. Li, X. Juan, J. Peng, et al., "The availability, price and affordability of antidiabetic drugs in Hubei province, China," Health policy and planning, vol. 33, pp. 937947, 2018.

[47]. D. R. Xu, W. Gong, E. D. Caine, S. Xiao, J. P. Hughes, M. Ng, et al., "Lay health supporters aided by a mobile phone messaging system to improve care of villagers with schizophrenia in Liuyang, China: protocol for a randomised control trial," BMJ open, vol. 6, p. e010120, 2016.

[48]. J. Liao, Y. Chen, Y. Cai, N. Zhan, S. Sylvia, K. Hanson, et al., "Using smartphone-based virtual patients to assess the quality of primary healthcare in rural China: protocol for a prospective multicentre study," BMJ open, vol. 8, p. e020943, 2018.

[49]. J. Tu, C. Wang, and S. Wu, "The internet hospital: an emerging innovation in China," The Lancet Global Health, vol. 3, pp. e445-e446, 2015.

[50]. C. Yang, L. Wu, W. Cai, W. Zhu, Q. Shen, Z. Li, et al., "Current situation, determinants, and solutions to drug shortages in Shaanxi Province, China: a qualitative study," PloS one, vol. 11, p. e0165183, 2016.

[51]. Y. Fang, "Pharmaceutical pricing policies in China," in Pharmaceutical Prices in the 21st Century, ed: Springer, 2015, pp. 43-58.

[52]. J. Dai, X. Wang, and F. J. Ayala, "Medical informatics and the "three long, one short" 
problem of large urban hospitals in China," Jama, vol. 316, pp. 269-270, 2016.

[53]. J. Hu and E. Mossialos, "Pharmaceutical pricing and reimbursement in China: when the whole is less than the sum of its parts," Health policy, vol. 120, pp. 519-534, 2016.

[54]. Y. Chi, C. Yu, X. Qi, and H. Xu, "Knowledge Management in Healthcare Sustainability: A Smart Healthy Diet Assistant in Traditional Chinese Medicine Culture," Sustainability, vol. 10, p. 4197, 2018.

[55]. Y. C. Dai Su, H. Gao, H. Li, L. Shi, J. Chang, X. H. Di Jiang, et al., "Does capitation prepayment based Integrated County Healthcare Consortium affect inpatient distribution and benefits in Anhui Province, China? An interrupted time series analysis," International journal of integrated care, vol. 19, 2019.

[56]. W. Fan, J. Liu, S. Zhu, and P. M. Pardalos, "Investigating the impacting factors for the healthcare professionals to adopt artificial intelligence-based medical diagnosis support system (AIMDSS)," Annals of Operations Research, pp. 1-26, 2018.

[57]. Y. Yang, X. Zhou, S. Gao, H. Lin, Y. Xie, Y. Feng, et al., "Evaluation of electronic healthcare databases for post-marketing drug safety surveillance and pharmacoepidemiology in China," Drug safety, vol. 41, pp. 125-137, 2018.

[58]. S. Guo, X. Guo, X. Zhang, and D. Vogel, "Doctor-patient relationship strength's impact in an online healthcare community," Information Technology for Development, vol. 24, pp. 279-300, 2018.

[59]. H. Yang and H. Gao, "Toward sustainable virtualized healthcare: extracting medical entities from Chinese online health consultations using deep neural networks," Sustainability, vol. 10, p. 3292, 2018.

[60]. D. He, R. Ye, S. Chan, M. Guizani, and Y. Xu, "Privacy in the Internet of Things for smart healthcare," IEEE Communications Magazine, vol. 56, pp. 38-44, 2018.

[61]. Y. A. Hong and Z. Zhou, "A profile of eHealth behaviors in China: Results from a national survey show a low of usage and significant digital divide," Frontiers in public health, vol. 6, p. 274, 2018.

[62]. B. Xu, L. Li, D. Hu, B. Wu, C. Ye, and H. Cai, "Healthcare data analysis system for regional medical union in smart city," Journal of Management Analytics, vol. 5, pp. 334-349, 2018.

[63]. X. Li, L. Fan, and S. X. Leng, "The aging tsunami and senior healthcare development in China," Journal of the American Geriatrics Society, vol. 66, pp. 1462-1468, 2018.

[64]. Q. Liu, K. Liao, and Z. Wei, "Automatic Acceptance Prediction for Answers in Online Healthcare Community," in 2018 IEEE International Conference on Bioinformatics and Biomedicine (BIBM), 2018, pp. 1262-1265.

[65]. W. Zhang, Z. Deng, Z. Hong, R. Evans, J. Ma, and $\mathrm{H}$. Zhang, "Unhappy patients are not alike: content analysis of the negative comments from China's Good Doctor website," Journal of medical Internet research, vol. 20, p. e35, 2018.

[66]. S. Negash, P. Musa, D. Vogel, and S. Sahay, "Healthcare information technology for development: improvements in people's lives through innovations in the uses of technologies," ed: Taylor \& Francis, 2018.

[67]. T. Q. Sun and R. Medaglia, "Artificial Intelligence Entering Public Healthcare Ecosystems: Do Policies Matter?," in 2017 PreICIS Workshop on e-Government, 2018.

[68]. T. Q. Sun and R. Medaglia, "Mapping the challenges of Artificial Intelligence in the public sector: Evidence from public healthcare," Government Information Quarterly, vol. 36, pp. 368-383, 2019.

[69]. D. Tao, J. Yuan, F. Shao, D. Li, Q. Zhou, and X. $\mathrm{Qu}$, "Factors affecting consumer acceptance of 
an online health information portal among young internet users," CIN: Computers, Informatics, Nursing, vol. 36, pp. 530-539, 2018.

[70]. B. Wu, "Patient continued use of online health care communities: web mining of patientdoctor communication," Journal of medical Internet research, vol. 20, p. e126, 2018.

\section{Cite this article as :}

Henry Asante Antwi, Tamires Lizandra Andrade Paixao, Maxwell Opuni Antwi, "Digitisation of Healthcare Products and the Democratization Continuum of the Healthcare System in China : A Systematic Review", International Journal of Scientific Research in Science, Engineering and Technology (IJSRSET), Online ISSN : 2394-4099, Print ISSN : 2395-1990, Volume 8 Issue 4, pp. 266-283, July-August 2021. Available at doi : https://doi.org/10.32628/IJSRSET218446

Journal URL : https://ijsrset.com/IJSRSET218446 